\title{
A Study on Sustainability Rate of Cropping Systems Commonly Used in Jahrom Region, Fars Province, Iran
}

\author{
Fatemeh Zarei* \\ MSC in Agriculture and Plant Breeding Engineering -Agro Ecology of University of Jiroft, Iran \\ *Corresponding author: Fatemehzarei111@gmail.com
}

\begin{abstract}
Maintenance and sustainability of agricultural products sources are considered as the significant principles of sustainable agriculture while healthy products and continuity in production are dependent on the development of sustainable agriculture. The main purpose of this study is to evaluate the sustainability rate of cropping systems which are commonly used in Jahrom region, Iran. The study is descriptive and analytic; making use of Cochran formula, the sample size was estimated as 100 individuals who were studied based on a questionnaire in multiple cropping system or poly-cropping and single cropping systems or monoculture (wheat). The results indicate that $58 \%$ of cropping systems tend to unsustainability in Jahrom region; just $12 \%$ of systems are categorized as sustainable while $30 \%$ of these cropping systems are relatively sustainable. Comparisons done on mean of sustainability indices in cropping systems show that the mean of sustainability in indices such as the type of cropping land, sustainable agriculture knowledge, function in a year and the attitude toward sustainable agriculture in multiple cropping systems are more significant than these indices in single cropping systems. In addition, Index of social participation (mean value) and ecological features in single cropping systems are more than these factors in multiple cropping systems. The estimated results of regression model indicate that the effective factors on sustainability of studied cropping systems include variables of land ownership, the entire cropping land, social participation, sustainable agricultural knowledge, and the obstacles in achieving sustainability in agriculture which covers and describes $70 \%$ of changes in dependent variables.
\end{abstract}

Keywords: Sustainable index, cropping systems, Jahrom region

Cite This Article: Fatemeh Zarei, "A Study on Sustainability Rate of Cropping Systems Commonly Used in Jahrom Region, Fars Province, Iran.” Applied Ecology and Environmental Sciences, vol. 5, no. 2 (2017): 60-66. doi: 10.12691/aees-5-2-5.

\section{Introduction}

The agriculture industry in the second half of the $20^{\text {th }}$ century has been quite successful in meeting the demands for food throughout the word, which also means that the natural resources (soil, water resources and genetic varieties) have been excessively exploited to the point of destruction by applying over tilling, single cropping systems, irrigation systems, fertilizers, insecticide and pesticide chemical controls and modifying crops genetics with no concern for the long term consequences which has endangered the ecological sustainability of cropping ecosystems [1]. Therefore, in recent decades different attitudes, opinions and studies related to sustainable development in exploiting agricultural resources have been developed [2]. Although the concept of sustainability, of course, is far from straightforward and different actors will have different views on what it entails [3], Conway believes that sustainable agriculture is the ability of ecosystem in preserving fertility of the soil (1987) and also keeping up with the ecological, economic and social dimensions [4]. Sustainable agriculture is an approach termed based on an equal pattern that guaranties sustainable economy, ecology and society [5].
Sustainability in agriculture is critical since it guarantees continued food production for the growing population [6], and plant ecology has much to contribute to the development of sustainable agricultural systems [7].

Thus, three main goals of sustainable agriculture are economic efficiency, quality environment and social responsibility, and each item is equally important [8]. Management and evaluation of agricultural systems is dependent on the indices which are necessary for decision making [9]. Management leads to optimal recycling of nutrients and organic matter turnover, closed energy flows, water and soil conservation and balance pest-natural enemy populations, all key processes in maintaining the agroecosystem's productivity and its self-sustaining capacity [10].

Sustainability values are quantitative values that help understanding environmental conditions and sustainability of agricultural systems [11]. Undoubtedly, in environmental friendly agricultural systems in future, sustainability indices will be the most important tools in managing agricultural systems, from the first steps- in designing the system- to the final step- agricultural products market. Therefore, by evaluating sustainability rate of agricultural systems and by outlining the development barriers, it is possible to set up feasible plans for improving sustainability in agricultural systems. In 
other words, specific local indicators are necessary for different regions to represent the sustainability status [6]. Although in many countries there are basic reference indices for national and regional agricultural sustainability, but in Iran such basic reference indices have not been yet developed. This is because of people's low awareness of the status of agricultural sustainability and also low rates of studies conducted in this field [12]. In Iran, little information is available concerning agricultural sustainability. On the other hand, some potential agricultural regions in Iran are endangered by instability due to the changes in the agricultural systems [13]. For this reason, evaluating sustainability rate of agricultural production systems has become a major topic in discussing ways to sustainable agriculture. Sustainability includes not only the environmental aspects but also the economic and social aspects. The significance of each of the aspects regarding sustainability is not equal [6]; while public agricultural extension system is currently not well oriented [14]. The role of public policy is to create the most favorable conditions to increase social engagement, and therefore participation in developing adaptation strategies to change [15]. It is embedded in a social context, problematizing capitalist relations of production and allying itself with agrarian social movements [16].

In some parts of the world, it is not only a scientifictechnological project, but a political one [10]. In this regard, in the first, second and the third economic, social and cultural development program and also in the Twenty Years Development Outlook Document of the Islamic republic of Iran, agricultural development and agricultural sustainability are highly emphasized. Since Jahrom region is an agricultural hub in Fars province and agriculture is the most important economic section of the region and also considering the fact that horticultural products play an important role in food security of the region, therefore it is necessary to pay a especial attention to sustainable agricultural systems in order to preserve the environment and also to prevent negative healthcare issues. The end of this paper is to study and evaluate the sustainability of cropping systems in Jahrom region since this knowledge will only be used if society has sustainability as one of its primary goals [7].

\section{Methodology}

Case study region: Jahrom is located in 185 kilometers southeast of Shiraz, the capital of Fars Province. Its climate is warm and semi-arid. Jahrom is in southwest of Shiraz, the capital of Fars Province. It has a land area of $5737 \mathrm{~m}^{2}$. The central section of the country shares border with Darab to the east, Lar and Firuzabad to the south, Simakan section of Jahrom and Firuzabad to the west and Kordian and Khafr sections of Jahrom to the north, where Kordian and Khafr sections of Jahrom share border with Fasa and Shiraz to the north [32].

Research plan: this is an applied research article using descriptive-analytic method. The statistical society of this study covers multiple cropping system or poly-cropping (citrus, palm trees and cucurbits) and single cropping systems or monoculture (wheat). Based on the Cochran formula, the sample volume is determined. Based on the goals and presumptions of the study, a questionnaire was prepared for data gathering. The questionnaire covered personal, social, ecologic, economic and cropping features, education and extension features, sustainable agriculture awareness, attitudes toward sustainable agriculture, the obstacles to sustainable agriculture and sustainable crops. In preparing the questionnaire, the variables change rates and statistical test were proportionally taken into consideration. The devised questionnaire contains 156 questions and its validity has been approved by agricultural specialists. After in-person interview with 30 local farmers in the crop year 2014-2015, they filled out the approved questionnaire. In order to reassure the validity of the questionnaire was retested. Therefore, after 15 days, the same 30 farmers were asked to refill the questionnaire, where the coefficient of the test turned out to be $78 \%$, which approved the reliability of the questionnaire for evaluating the sustainability rate of cropping systems. In this study, reliability index is dependent variable and independent variables would be indices such as economic, social, cropping, personal features, market availability, communication facilities, educational and training activities and propagation, knowledge of sustainable agriculture and attitudes toward it, barriers to sustainable agriculture. In order to evaluate sustainability rate of cropping systems in the region, 17 questions were designed based on the 5 point Likert scale questionnaire sample; four (strongly agree), three (agree ), two (undecided), one (disagree), zero (strongly disagree). Based on this scale, the best situation receives the highest score and the worst situation receives the least score. By a simple estimation of the variables in the cropping system, it is possible to determine that if the cropping system is going for sustainability or against it. Sustainability rate variables are function of mathematical calculations of positive effective variables, X1-X15 (including crop rotation, using legumes, using green manure, using animal manure, using cover crops, mechanization rate, perforated plowing, planning strong varieties, preserving plants remains, combined management of crop pests, managing water resources, using fallow systems, mechanical pest control, managing surface waters and preserving cover plants), and also effective negative variables, Y1, Y2 (including using chemical pesticides and chemical fertilizers). After estimation of positive and negative variables in sustainability of cropping systems and equalizing the units, the variable sustainability of cropping systems (S) for a farm is calculated through $\mathrm{S}=\sum_{i-1}^{x i} \mathrm{X}_{\mathrm{i}}-\sum_{y-1}^{y i}$. Where the larger the value of $\mathrm{Xi}$, the more sustainable the cropping system is and the larger the value of $\mathrm{Yi}$, the less sustainable the cropping system would be.

The quality of sustainable agriculture by using ISDM index [17] based on average and standard deviation is calculated.

Equation (1). The farms in different types are divided in to four sections according to their sustainability rate; $\mathrm{A}=$ most unsustainable, $\mathrm{B}=$ unsustainable, $\mathrm{C}=$ sustainable, $\mathrm{D}=$ most sustainable.

Equation (1).

A: negative Min $\leq \mathrm{A}<$ Mean - St.d

B: relatively negative Mean - St.d $\leq \mathrm{B}<$ Mean 
C: relatively positive Mean $\leq \mathrm{C}<$ Mean + St.d

D: positive Mean + - St.d $\leq \mathrm{D}<$ Max

Multivariate regression model is used to measure the effective factors on sustainability, where its simple equation is:

Equation (2) $Y i=B 0+B 1 X 1+B 2 X 2+B 3 X 3+\ldots .+B 17$ $X 17$

Based on this method sustainability index is dependent index and the indices investigated are independent variables, and the variables which did not have great impact on the equation were removed. Then, based on the multivariate linear regression model, the equation coefficients are calculated and sustainability index is obtained.

\section{Results}

\subsection{Descriptive Results of Independent Quantitative Variables in Multiple Cropping Systems (citrus, palm trees and cucurbits)}

Personal Features: the reported average age for the farmers is 53 , the oldest is 81 and the youngest is 26 . The highest frequency is age $60-70$ that is $24.6 \%$ of the farmers. An investigation of farmers' education shows that the majority of them, $32.4 \%$ have elementary education, ranging first to third grade. Only $11.4 \%$ of the farmers had university or collage education and $14.3 \%$ of them were illiterate. The majority of the farmers with multiple cropping systems (citrus, palm trees and cucurbits) had 110 year cropping record and the highest record is 60 years and the lowest record is 4 years cropping cucurbits including $19.08 \%$ of the farmers.

Cropping Features: on average, $1.4 \%$ of the individuals do farming, $2.9 \%$ of the individuals do farming and animal husbandry, and $45.7 \%$ of the individuals do farming and gardening, $35.7 \%$ of the individuals do farming, animal husbandry and gardening, and $14.3 \%$ of the individuals do other activities. $75.7 \%$ of the individuals are land owners, 11 individuals work on leasehold land, and $12.9 \%$ of the individuals do share cropping. The study of cropping systems shows that $10 \%$ of the lands are left fallowed, $20 \%$ of the lands are alternatively legumized and cucurbitized, $38.6 \%$ of the lands are alternatively fallowed, and $24.3 \%$ of the lands are cultivated continuously, and $7.1 \%$ of the lands are no arable. Also, the average land area an individual owns is 8 acres, while the largest land is 21 acres and the smallest is 1 acre.

Economic Features: Of the three products -citrus, palm trees and cucurbits- the highest average income rate belongs to citrus fruits with 820 million Rials. Citrus fruits had the highest income of 200 million, while the lowest income rate of 1 million belonged to cucurbits. 16 individuals did not have any production other than citrus fruits and dates. Average citrus production per hectare stands at 14.5 tons, while the highest yield rate is 50 tons per hectare and the lowest yield rate is 2 tons per hectare, and the majority of the individuals reported yields 10-20 tons per hectare. Average dates yield per acre is 7.5 tons.
The highest frequency rate goes to the individuals who experienced 5-10 tons yield per hectare. The highest yield rate for dates is 20 tons per hectare and the lowest yield rate is 0.5 tons per hectare. $60 \%$ of the farmers do not have any other income than farming.

\subsection{Descriptive Results of Ranked Variables of Multiple Cropping Systems (citrus, palm trees and cucurbits)}

The results show that $39 \%$ of the farmers have a low rate of education and extension activities, and $47 \%$ of the farmers have high rate of education and extension activities, and $14 \%$ of them have higher rate of education and extension activities which means that these activities have great effect on more than half of the individuals. $63 \%$ of the farmers' knowledge concerning sustainable agriculture is below the average. $21 \%$ of the farmers have a good agricultural knowledge, and $16 \%$ of the farmers have high agricultural knowledge. This shows that the farmers have a low awareness and knowledge concerning sustainable agriculture. The general awareness of $55.7 \%$ of the farmers about sustainable agriculture is below the average point, and awareness of $43.3 \%$ of the farmers high. Therefore it is necessary to identify these individuals and educate them and increase their agricultural knowledge so that they can help improve agricultural sustainability through education and extension activities.

\subsection{Descriptive Results of Quantitative Independent Variables in Single Cropping Systems}

Personal features: Farmers' average age is 48.43 years. The oldest farmer is 87 years old and the youngest is 27 years old. The most frequent ages are 50-60, including $33.3 \%$ of the farmers. $36.7 \%$ of the farmers' education ranging from high school first stage to diploma. $20 \%$ of the farmers are illiterate and $20 \%$ of them have university education. The highest frequency in wheat planting goes to farmers with 1-20 years of experience. The average years of experience in wheat planting is 22.40 years, and the highest experience is 70 years, and the lowest is 3 years, and the average experience years is 22.40.

Cropping Features: The study results show that $53.3 \%$ of the individuals do farming, $26.7 \%$ of the individuals do both farming and animal husbandry, $13.3 \%$ of the individuals do farming and gardening, and $6.7 \%$ of the individuals do farming, animal husbandry and gardening. Concerning the ownership of the lands, according to the results $83.3 \%$ of the individuals owned the lands as personal property, while $16.7 \%$ of the individuals had rented the lands. The results also show that $43.5 \%$ of the lands were left fallowed, $36.7 \%$ of the lands are alternatively fallowed, $13.3 \%$ of the lands were used alternatively. The average area of land each farmer owns is 8.53 hectares, where the largest land is 20 hectares and the smallest land is 3 hectares.

Economic Features: Based on the results, farmers' maximum income is 90 millions and the minimum income is 20 millions, and the average income is 49 million. The highest frequency rates goes to individuals with 40-60 
millions income which compose $46.7 \%$ of the farmers. The average wheat yield per hectare is 5.9 tons, where the highest yield rate is 7 tons per hectare and the lowest yield rate is 4 tons per hectare, and the highest frequency goes to farmers with 5-6 tons yield rate per hectare. The year average wheat yield rate is 49.6 tons per hectare. The maximum yield rate per year is 100 tons and the minimum yield rate per year is 18 tons, and the highest frequency rate goes to farmer with $30-70$ ton wheat yield per year. $60 \%$ of the farmers do not have any other income than farming.

\subsection{Descriptive Results of Step Variables in Single Cropping Systems}

Education- extension based activities in more than half of the individuals were less than the normal average range and only in $16.7 \%$ of the individuals were higher than average, which reflects that these activities had been as effective as expected. More than $40 \%$ of the farmers' knowledge of sustainable agriculture was below average point. $50 \%$ of the farmers had a good knowledge of sustainable agriculture and only $10 \%$ of them had a rather higher knowledge of sustainable agriculture, which reflects that the farmers' knowledge of sustainable agriculture is generally good. The results also show that $46.6 \%$ of the farmers have a low attitude to sustainable agriculture, and $53.4 \%$ of them have a high and rather higher knowledge of sustainable agriculture.

Classifying sustainability of agricultural systems: the sustainability rate of the farms is calculated according to the two studied agricultural systems and variables that are effective in agricultural productions, and finally based on the average rate of 33.31 for sustainability and with a rate of 4.51 for standard deviation of sustainability index, the farms are divided in to four sections of unsustainable, fairly unsustainable, fairly sustainable, and sustainable (see Table 3). According to the results, $5 \%$ of the farms are classified as unsustainable, $53 \%$ of the farms are classified as fairly unsustainable, $30 \%$ of the farms are classified as fairly sustainable, and $12 \%$ of the farms are classified as sustainable. The sustainability of $58 \%$ of the farms was below the average level, and $42 \%$ of the farms above the average level, which indicates that the agricultural systems are rather unsustainable.

The fair unsustainability of the cropping systems is because of the fact that $16 \%$ of the farmers are illiterate and $16 \%$ of them only have had elementary education, and also $44 \%$ of the farmers are rather old, aging 54-87 years old, for whom complying with the rules of sustainable agriculture is rather difficult. On the other hand, sustainable agriculture is more acceptable to young farmers. Also, $60 \%$ of the farmers live only on farming and do not have any other source of income, and their economic security is endangered by regional tensions and decrease in agricultural productions due to drought as one of the main challenging issues in agriculture.

\subsection{A Comparison of the Average Rates of Sustainability Indices in Single Cropping and Multiple Cropping Systems}

In order to compare the average rates of sustainability indices in single cropping and multiple cropping systems, two separate $\mathrm{T}$ tests are taken. The independent variables of the study, and also the total sustainability index of agricultural systems are put in to the test, in order to both compare the two systems, and to ensure the validity of the classified index (ISDM index). According to the Table 4; the comparison of the average indices of the productions of the two systems -including agricultural system type average, knowledge of sustainable agriculture, product yield per year, attitude to sustainable agriculture- showed that there is a significant difference between single cropping systems and multiple cropping systems. This difference is statistically significant. According to the Table 4, the comparison of the average rates show that multiple cropping systems hold a better position and are in a better condition. The comparison of the average indices in social participation and ecological feature show Also that multiple cropping systems are significantly different from single cropping systems, where the average rates of indices in multiple cropping systems are greater than single cropping systems. Therefore, according to the results from the comparison, the average indices in single cropping systems hold a better position.

Table 1. Descriptive results of ranked variables of multiple cropping systems

\begin{tabular}{|c|c|c|c|c|c|}
\hline Variables & Average & $\begin{array}{l}\text { Standard } \\
\text { deviation }\end{array}$ & Minimum & Maximum & Frequency Distribution \\
\hline Education- extension activities & 8.91 & 1.8 & 4 & 14 & $21(4-7.04), 18(7.04-8.91), 47(8.91-10.78), 14(10.78-14)$ \\
\hline $\begin{array}{l}\text { sustainable agriculture } \\
\text { knowledge }\end{array}$ & 69.35 & 6.8 & 56 & 88 & $\begin{array}{c}12(56-62.13), 51(62.13-69.35), 21(69.35-76.22) \\
16(76.22-88)\end{array}$ \\
\hline $\begin{array}{l}\text { Attitude to sustainable } \\
\text { agriculture }\end{array}$ & 54.38 & 4.38 & 46 & 72 & $\begin{array}{c}11.4(46-49.9), 44.3(49.9-54.3), 31.4(54.3-58.75), \\
12.9(58.75-72)\end{array}$ \\
\hline
\end{tabular}

Table 2. Descriptive results of step variables in single cropping systems

\begin{tabular}{|c|c|c|c|c|c|}
\hline Variables & Average & $\begin{array}{c}\text { Standard } \\
\text { deviation }\end{array}$ & Minimum & Maximum & Frequency Distribution \\
\hline Education- extension activities & 9.1 & 1.3 & 7 & 12 & $10(7-7.7), 53.3(7.7-9), 20(9-10.4), 16.7(10.4-12)$ \\
\hline $\begin{array}{c}\text { sustainable agriculture } \\
\text { knowledge }\end{array}$ & 67.8 & 4.27 & 58 & 78 & $10(58-63.5), 30(63.5-67.8), 50(67.8-72), 10(72-78)$ \\
\hline $\begin{array}{c}\text { Attitude to sustainable } \\
\text { agriculture }\end{array}$ & 51.5 & 5.06 & 37 & 58 & $\begin{array}{c}3.3(37-46.4), 43.3(46.4-51.5), 46.7(51.5-56.5), 6.7(56.5- \\
58.5)\end{array}$ \\
\hline
\end{tabular}


Table 3. The sustainability of agricultural systems case studies

\begin{tabular}{|c|c|c|c|c|c|c|c|}
\hline \multirow{2}{*}{ Sustainability level } & \multirow{2}{*}{ Range } & \multicolumn{2}{|c|}{ multiple -cropping } & \multicolumn{2}{|c|}{ Single cropping } & \multicolumn{2}{|c|}{ Total } \\
\hline & & Frequency & Percentage & Frequency & Percentage & Frequency & Percentage \\
\hline unsustainable & $22-28.8$ & 5 & 7.1 & - & - & 5 & 5 \\
\hline fairly unsustainable & $28.8-33.31$ & 37 & 52.9 & 16 & 65 & 53 & 53 \\
\hline fairly sustainable & $33.31-37.82$ & 20 & 28.6 & 10 & 25 & 30 & 30 \\
\hline sustainable & $37.82-51$ & 8 & 11.4 & 4 & 10 & 12 & 12 \\
\hline
\end{tabular}

Table 4. The results of comparison of the average rates of sustainability indices in case study cropping systems

\begin{tabular}{|c|c|c|c|}
\hline variables & & Average rates & Results of average comparison tests \\
\hline \multirow[b]{2}{*}{ Cropping system type } & multiple cropping & 3.58 & A \\
\hline & single cropping & 1.7 & $\mathrm{~B}$ \\
\hline \multirow[b]{2}{*}{ Social participation } & multiple cropping & 10.35 & $\mathrm{~B}$ \\
\hline & single cropping & 12.43 & A \\
\hline \multirow[b]{2}{*}{ Ecological features } & multiple cropping & 44.25 & $\mathrm{~B}$ \\
\hline & single cropping & 65.08 & A \\
\hline \multirow[b]{2}{*}{ Agricultural knowledge } & multiple cropping & 69.35 & A \\
\hline & single cropping & 67.80 & $\mathrm{~B}$ \\
\hline \multirow[b]{2}{*}{ Yield per year } & multiple cropping & 60.2 & A \\
\hline & single cropping & 36.2 & $\mathrm{~B}$ \\
\hline \multirow[b]{2}{*}{ Attitude to sustainable agriculture } & multiple cropping & 54.37 & A \\
\hline & single cropping & 51 & B \\
\hline
\end{tabular}

Effective factors in sustainability of case study cropping systems as a dependent variable and independent variables in this study (including: farmers age, performance, agricultural experience, attitude to sustainable agriculture, obstacles to sustainable agriculture, social participation, land ownership, the total farm land, yield rate, contact with promoter) are tested and analyzed step by step in multiple regression in SPSS software. The value of $F$ shows that the calculated regression is statistically significant. In the multi variable regression, the variables of ownership, farm land, social participation, and knowledge of sustainable agriculture have positive effect on sustainable agriculture in Jahrom, and obstacles to sustainable agriculture have negative effect on sustainable agriculture in Jahrom. These variables which have the highest effect on the change rate of dependent variables remain in the final model and the rest of variables are removed off the equation. According to the calculated value of $\mathrm{R} 2$, more than $70 \%$ of change rate in the sustainability of the case study farms is due to the five independent variables of the model. Table5 shows the related analysis. The value of coefficient of the variable of knowledge of sustainable agriculture reflects that, with the presumption of other variables remained static, $1 \%$ increase in knowledge of sustainable agriculture can increase the average index of sustainability for 0.365 , which means that the an increase in the individuals' agricultural knowledge, can increase farms sustainability. Since the sustainable agriculture knowledge of the farmers in this study does not have a desirable condition (more than $60 \%$ of the farmers stand below the average rate), this could make the farms more unsustainable. Making agriculture sustainable requires a food production system that has sustainability as one of its primary goals [7]; therefore, by enhancing the sustainable agriculture knowledge of the farmers, the sustainability of the cropping systems could be guaranteed.

Table 5. the result of regression model for evaluating effective factors on sustainability index of cropping systems

\begin{tabular}{|c|c|c|c|}
\hline variable & coefficient & T statistics & Significance level \\
\hline y intercept & & 0.018 & 0.312 \\
\hline Land ownership & 0.275 & 2.73 & 0.008 \\
\hline Total farm land & 0.276 & 2.28 & 0.025 \\
\hline Social partnership & 0.224 & 2.39 & 0.019 \\
\hline Agricultural knowledge & 0.365 & 3.68 & 0.000 \\
\hline Obstacles to agriculture & -0.195 & 1.979 & 0.045 \\
\hline F statistics & & 3.17 \\
\hline R2 & Fignificance level 0.001 \\
\hline
\end{tabular}

\section{Conclusion}

Developing countries have seriously low adoption rates of sustainable agricultural practices (SAPs) and there is a need to understand why [18]. Although today farmers in most of the countries worldwide have a higher knowledge of agriculture compared to decades ago, and undoubtedly they are more aware of issues such as sustainable agriculture and environmental protection, and they pay attention to these issues in their cropping systems, nothing demonstrates the huge gap between ecological sustainability 
and current farming practices than the very restricted rotations we observe in most modern temperate agricultural systems [7]. Studies show that the farmers who have a higher knowledge of agriculture are more attracted towards modern technological advances in agricultural productions [19]. Based on the values of variables' coefficient, and its impact on the dependent variable, knowledge of sustainable agriculture is very important, which indicates the importance of farmer's knowledge of sustainable agriculture in developing sustainable agricultural systems. These findings are compatible with the findings of Cristoiu, Lucena and Caceres [20], Seddighi and Roosta [21] and Karami [22].

Selected crop pattern which influences on the feasibility of sustainable agricultural practices influences environmental and economic condition and affects sustainability profoundly in agricultural practices [23]. In the case study region, $12 \%$ of the cropping systems were classified as sustainable, $30 \%$ of them were classified as fairly sustainable, which indicates that the region's cropping systems are fairly unsustainable. Kucheki [38] and Purzand [24] in similar studies have declared the cropping systems of Khorasan and Jahrom as unsustainable.

Based on the findings of this study in analyzing and comparing average index rates of sustainability in single and multiple cropping systems, proposals for improving sustainability in single and multiple cropping systems are offered; based on the findings the sustainability rate of cropping systems in Jahrom region is low, so it is recommended that the city agriculture authorities pay more attention to this issue, and give single cropping systems (wheat) a higher priority than multiple cropping systems (citrus, palm trees and cucurbits). Since more than $40 \%$ of the farmers are old and have low levels of education, it is recommended to pave the way for young agriculture graduates by providing them required facilities and also create job opportunities for them in the agriculture industry. Based on the coefficient, the sustainable agriculture knowledge variable plays an important role in farms' sustainability, therefore it is recommended that Jahrom agriculture authorities review their education and extension plans with special regard to agricultural sustainability in educational plans for farmers. Since in majority of the cases the ownership of the lands belongs to the farmers themselves, it is recommended that agriculture authorities hold educational classes concerning improvement of cropping systems sustainability in the farm sites. Since, according to the findings, social participation provides the opportunities for the farmers to become informative of the latest innovations in agriculture and has positive effects on sustainability and that social participation rate of half of the farmers was low, so it is recommended to identify the barriers to social participation and remove them in order to improve cropping systems sustainability. The analysis of effective factors on cropping systems sustainability in this study show that ownership also has a positive effect on agricultural sustainability, which means that the farms that are owned by the individual farmer are more sustainable than other farms. In this study, the results indicate that $85 \%$ of the lands are private ownership. This result is similar to the findings of Bagheri [25], Souza, Cyphers and Phipp [26], Damghani [27]. On the other hand, the positive variable of area of the cropping land indicates that the larger the land, the higher instability would be. This result is also similar to the findings of Bagheri [25], Cristoiu, Lucena and Caceres [20], but in terms of social participation $56 \%$ of the individuals turned out to be poor. Obstacles to sustainable agriculture have negative effect on farms sustainability, and obstacles decrease agricultural sustainability. The results of this study are similar to the findings of Rezaei, Moghadam and Karami [28] and Hooshang Iravani [29]. Thus, the authorities of department of agriculture should do their best to remove the obstacles and take effective actions in improving cropping systems sustainability. The findings in this study show that multiple cropping systems have a higher rate of sustainability than single cropping systems.

According to the results, there is a significant relationship between the variable of farmers' social participation and farms' sustainability index, which indicates that an increase in social participation of the farmers will improve the farms' sustainability. Thus, encouraging and engaging the farmers in to cooperative and collaborative activities would be a good step forward to sustainability of agricultural systems in the region. The findings in this study show that the social participation of more than $56 \%$ of the farmers is below the average rate. This might be due to the farmers' old age, based on the fact that older people tend to show a lower social participation rate. However, by considering their viewpoints and seeking their cooperation, it is possible to create new ways to agricultural sustainability [39]. The area of the land has an important effect on the index of sustainability. The positive variable of area of the land reflects that the larger the land, the more sustainable is could be. The area of $52 \%$ of the lands ranged 5-10 hectares. On the other hand, large lands make it possible for large and advanced machinery to work, which increases the agricultural efficiency and productions by large, and the farmer will enjoy a higher income. Of course it should be mentioned that, large lands can increase agricultural sustainability only when environmental care issues and also environment friendly equipment and technologies are used on the land [32]. The obstacles to sustainable agriculture have a direct negative effect on the sustainability index of the studied lands, so that the more obstacles to sustainable agriculture, the less sustainable the farms would be. The common obstacles to sustainable agriculture are illiteracy of $16 \%$ of the farmers and being ignorant of scientific solutions to sustainable agriculture, easiness of traditional agriculture and poor economic conditions of the farmers.

\section{References}

[1] Glissman, S., Agroecosystems Sustainability: Developing Practical Strategies. Boca Raton, CRC Press, 2001.

[2] Tatlidil, F.F., Boz, I., and Tatlidil, H., Farmers' perception of sustainable agriculture and its determinants: a case study in Kahramanmaras province of Turkey, Environ Dev Sustain. 2009, 11, 1091-1106.

[3] Elzen, B., A., Augustyn, M., Barbier, and B., van Mierlo, AgroEcological Transitions: Changes and Breakthroughs in the Making, Ageningen University \& Research, Applied Arable and Vegetable Research, 2017, 143-159. 
[4] Altieri MA (1987) Agroecology: The scientific basis of alternative agriculture. Westview Press Bouldr, COConway GR. 1987. The properties of agro ecosystems. Agric Syst. 1999, 24, 95-117.

[5] D’Silva J.L., Abu Samah, B., Uli, J., and Hayrol Azril, M.S., Acceptance of sustainable agricultural practices: The case of crop farmers. American Journal of Agricultural and Biological sciences. 2011, 6, 227- 230.

[6] Houshyar, E., Smith, P., Mahmoodi-Eshkaftaki, M., and Azadi, H., Sustainability of wheat production in Southwest Iran: A fuzzy-GIS based evaluation by ANFIS, Cogent Food \& Agriculture, 2017, 3: 1327682; pp.2-18.

[7] Weiner, J., Mini-Review: Ecological Solutions to Global Food Security Applying plant ecological knowledge to increase agricultural sustainability, Journal of Ecology, 2017, 105, 865-870.

[8] Karami, E., Manso, O.R., and Abadi, A., Sustainable agricultural attitudes and Behaviors: Aqender analysis of Iranian farmers. Journal of Environment Development and Sustainability, 2008, 10, 883-898.

[9] Girardin, P., Bockstaller, C., and VanderWerf, H.M.G., Indicators: Tools to evaluate the environmental impacts of farming systems. J Sustain Agric. 1999, 13, 5-21.

[10] Miguel, A., Altieri, Clara, I., Nichollsand Rene, M., Technological Approaches to Sustainable Agriculture at a Crossroads: An Agroecological Perspective, Sustainability, 2017, 9, 349.

[11] Pannell, D.J., and Schilizzi, S., Sustainable agriculture: a matter of ecology, equity, economic efficiency or expedience. Journal of Sustainable Agriculture. 1999, 13, 57-66.

[12] Praneetvatakul, S., Janekarnkij, P., Potchanasin, C., and Prayoonwong, K., Assessing the sustainability of agriculture (A case of Mae Chaem Catchment, northern Thailand). Environment International. 2001, 27, 103-109.

[13] Chen, Z., Li, H., and Wong, C.T.C., Environmental Planning: Analytical Network Process Model for Environmentally Conscious Construction Planning. ASCE Journal of Construction Engineering and Management. 1998, 131, 92-101.

[14] Bellarbya, J., Sicilianob, G., Smithb, L.E.D., Xinc, L., Zhoue J., Liud, K., Jiec, L., Mengd, F., Inmanb, A., Rahnf, C., Surridgea B., Haygarth, P.M., Strategies for sustainable nutrient management: insights from a mixed natural and social science analysis of Chinese crop production systems, Environmental Development, 2017, 21, 52-65.

[15] Ruiu, M. L., Seddaiu, G., Roggero, P. P., Developing adaptive responses to contextual changes for sustainable agricultural management: The role of social capital in the Arborea district (Sardinia, Italy), Journal of Rural Studies, 2017, 49, 162-170.

[16] Holt-Gimenez, E, Altieri, M.A., Agroecology, Food Sovereignty, and the New Green Revolution. Agroecol. Sustain. Food Syst. 2013, 37, 90-102.

[17] Qamar, M., Global trends in agricultural Extension: challenges facing Asia and the pacific region. Keynote paper presented at FAO regional Expert consultation on agricultural extension, Bangkok, 2002.

[18] Tey, Y. S., Li E., Bruwer J., Abdullah A. M., Brindal M., Radam, A., Ismail, M. M., Darham, S., Factors Influencing the Adoption of Sustainable Agricultural Practices in Developing Countries: a Review, Environmental Engineering and Management Journal, 2017, 16 (2), 337-349. 13.

[19] Lashkarara, F., A Study of Attiftude of Top Farmers and Non-top Farmers to Sustainable Agriculture. MA Thesis, Department of Agriculture, Tarbiat Modares University, 2000.

[20] Cristoiu, A., Lucena, B., and Caceres, F., Farm-level determinations of conversion to sustainable farming practice in the new members states. Paper Prepared for Presentation at the Joint IAAE Budapest, Hungary, 2007.

[21] Sedighi, H., Roosta, K., Analysis of Effective Factors on Sustainable Agriculture Knowledge, Case Study: Fars Province Corn Farmers. Iranian Scientific Agriculture. 2003, 4, 913-924.

[22] Hayati, D., Karami, A., Effective Structures on Sustainable Agriculture Knowledge and Cropping Systems Sustainability (Case Study: Wheat Farms of Fars Province). Agricultural Science and Technology and Natural Resources Quarterly. 1999, 3, 21-33.

[23] Qureshi, M.N., Singh, R.K., \& Hasan, M.A., Decision support model to select crop pattern for sustainable agricultural practices using fuzzy MCDM, Environ Dev Sustain. 2017, 1-19.
[24] Purzand, M., Bakhshoodeh, M., Evaluating Agricultural Sustainability in Fars Province through Joint Olan Approach. Economic Agriculture Research Centre, 2012, 1, 10-15.

[25] Bagheri, A., Shabanali, Fami H., Rezvanfar, A., Asadi, A., and Yazdani, S., Perceptions of Paddy Farmers towards Sustainable Agricultural Technologies: Case of Haraz catchments area in Mazandaran province of Iran. American Journal of Applied Sciences. 2008, 5, 1384-1391.

[26] Souza, D.G., Cyphers D. M., and Phipp, T., Factors Effecting the Adoption of Sustainable Agriculture Practices. Agricultural and Resource Economics Review. 1998, 22, 159-165.

[27] Damghani, M., Kucheki, A., and Mahalati, N., Compiling a Sustainability Index for Evaluating Sustainability of Wheat-Cotton Systems in Khorasan Province. Iranian Scientific Agriculture Research Center. 2005, 5, 129-142.

[28] Rezaei Moghadam, K., and Karami, A., Destitution and Sustainable Agriculture, An Analysis of Rural Development. 1998 $2,1-10$.

[29] Iravani, H., Darban, A., Measuring, Analysis and E-planation of Production Units. Iranian Scientific Agriculture. 2007, 35, 52-3.

[30] Beshagh, M., Taghdisi, A., and Toosi, R., Evaluating Effective Factors in Agricultural Sustainability, Rular Research and Plan Center, 2014, 2, 1-10.

[31] Karami, A., The Workings of Economic-Social Structures in Agricultural Sustainability and Technical Knowledge in Wheat Farmers. Deputy of Plan and Budget, Ministry of Agriculture, 2011.

[32] Karami, A., Jahrom Studies, Jahrom, Iran, 2011

[33] Adeli Sarduei, M., Evaluating Agricultural Operations and Effective Factors in Jiroft City. MA Thesis, Tabriz University, 2009.

[34] Arabioon, A., Kalantari, K., and Asadi, A., Measuring Sustainability of Wheat Cropping Systems and Effective Factors on it in Fars Province. Iranian Education and Promotion of Scientific Agriculture. 2009, 2, 17-28.

[35] Van Passel, S., Nevens, F., Mathijs, B., and Van Huylenbroek, G., Measuring farm sustainability and explaining difference in sustainable efficiency. Ecological Economics. 2007, 62, 149- 161.

[36] Vahedi, M., Hosseini, M., Hosseini, J., Mirdamadi, M., Analysis of Nazarabad County Farmers' Point of View regarding Sustainable Agriculture Mental Indices on the Level of Farmers' Families, Journal of Economic Researches and Development of Agriculture in Iran, 2006, 2:123-133.

[37] Mousavi, A., Analyzing Effective Factors on Sustainable Agriculture in Wheat Farmers of Sistan and Baloochestan Province. M.A. Thesis, Islamic Azad University, Research and Science Branch, Tehran, 2005.

[38] Kucheki, A., Sustainable Agriculture, knowledge or Method. Agricultural Economy and Development Journal. 2004, 62, 20.

[39] Kucheki, A., Nasiri Mahalati, M., Moradi, R., Zonation of Sustainable Agriculture in Iran and Stable Strategies. Journal of Scientific Agriculture and Sustainable Production. 2004, 23, 179-197.

[40] Vahedi, M., Effective Factors on Wheat Insurance Acceptance and Analyzing Problems and Denial Reasons in Tafresh. MA Thesis, Faculty of Economics and Agricultural Development. Tehran University, 2002.

[41] Farshad, A., and Zinck, J.A., Assessing agricultural sustainability using the six-pillar model: Iran as a case study. Developing Practical Strategies, Florida, 2001.

[42] Rasoli, H., Analyzing Effective Factors on Farmers Engagement in Wheat Extension Activities in Garmsar. MA thesis, Islamic Azad University, Science and Research Branch, Tehran, 2000.

[43] Karami, A., Sustainable Development and Politics of Agriculture (Articles of the Iranian Politics of Agriculture Second Symposium). Shiraz, Iran.

[44] Webster, J.P.G., Assessing the economic consequences of sustainability in agriculture. Agriculture, Ecosystems Environment 1997, 64: 95-102.

[45] Conway, G.R., The properties of agro ecosystems. Agric Syst. 1987, 24, 95-117.

[46] Liverman, D.M., Hanson, M.E., Brown, B.J., and Merideth, R.W., Global sustainability: towards measurement. Environmental Management. 1988, 12, 133-143. 